\title{
DOSSIÊ TECNOLOGIAS E EDUCAÇÃO: NOVOS OLHARES E PERCEPÇÕES
}

DOSSIÉ TECNOLOGÍAS Y EDUCACIÓN: NUEVOS OJOS Y PERCEPCIONES

\author{
DOSSIÊ TECHNOLOGIES AND EDUCATION: NEW LOOKS AND \\ PERCEPTIONS
}

\author{
José Anderson Santos CRUZ ${ }^{1}$ \\ Lucas Justiniano BERMEJO ${ }^{2}$
}

(Orgs.)

\section{APRESENTAÇÃO}

A sociedade está em transformação, seja no aspecto social, econômico, político, e por sua vez, na educação. Essas transformações, de certo modo, acarretam novos olhares e percepções no contexto educacional quanto à formação do sujeito para atuar como cidadão e no âmbito mercadológico - modelos de negócios educacionais, a educação e os processos de ensino e aprendizagem, as questões do projeto político pedagógico para o ensino superior, a educação como produto, a educação como direito ao cidadão e as políticas públicas, as questões que permeiam a educação ou ensino a distância; podem ou não influenciar diretamente na formação do sujeito, principalmente com as tecnologias e a convergência tecnológica que estão cada vez mais no cotidiano do sujeito.

Com isso gera-se preocupações, por exemplo, como a educação pode intervir na formação do sujeito? Quais os impactos que as Tecnologias de Informação e Comunicação (TIC) causam na sociedade, na educação, na formação do professor, na formação do estudante? Qual o conceito de inovação educacional para o uso de estratégias para a implantação de novas metodologias de ensino? Como podemos avaliar a qualidade de ensino e aprendizagem com a mediação das TIC? As TIC promovem a reflexão e a criticidade do aluno? Como podem ser implementadas as metodologias ativas no cotidiano escolar e na vida do estudante? Qual o papel do

\footnotetext{
${ }^{1}$ Universidade Estadual Paulista (Unesp), Araraquara - SP - Brasil. Doutorando em Educação Escolar pela Faculdade de Ciências e Letras, FCLAr. Bolsista Capes. Professor e orientador dos cursos de Pósgraduação na Faculdade Anhanguera de Bauru (2014-2017). Mestre em TV Digital pela FAAC/Unesp. Consultor em editoração científica. E-mail: joseandersonsantoscruz@gmail.com

${ }^{2}$ Faculdade Anhanguera de Bauru, Bauru - SP - Brasil. Docente e Coordenador Pedagógico. Mestre pela USP/Bauru. E-mail: lucasjbermejo@hotmail.com
} 
professor-educador? A educação, o acesso, a apropriação da informação e do conhecimento; quem são os atores sociais ou os agentes públicos nessa jornada?

Diante disso, promover as discussões e, a partir de uma leitura reflexiva e crítica, avaliar o cenário educacional brasileiro para além das suas fronteiras, contribuirá para avançarmos nas reflexões em vários aspectos e contextos educacionais, contribuindo para uma sociedade autônoma capaz de tomar decisões com mais concretude nos mais variados cenários.

O tema em questão é abrangente, além disso, inesgotável, pois cada experiência em diferentes momentos e lugares, tanto nos grandes centros quanto nos mais remotos, são, de certa forma, singulares.

\section{Educação e tecnologias a partir de olhares e percepções em diversos contextos}

O dossiê "Tecnologias e educação: novos olhares e percepções" aborda uma visão diversificada da educação, tratando de temáticas que envolvem TIC e comunicação para aprimorar o desenvolvimento do ensino-aprendizagem.

Elaborado para obter um acentuado aprofundamento sobre o contexto, o dossiê se apresenta de uma maneira muito plural, elucidando a tecnologia e a comunicação como instrumentos que fazem diferença na validação do ensino básico e superior, na esfera presencial e à distância.

Tecnologias de Informação e Comunicação (TIC) exercem um papel muito importante na forma que nos comunicarmos e aprendemos. É um desafio conseguir atingir as necessidades dos discentes utilizando métodos alternativos de aprendizagem.

Dentre as várias temáticas propostas pelos trabalhos aqui publicados, temos a advertência feita por Lastória FCLAr/Unesp no primeiro artigo deste Dossiê, que se dirige àqueles que sabem da irreversível presença das tecnologias de última geração nas diversas esferas da vida social, e que creem que a autonomia, o bom senso e a justa medida devem ser os primeiros condutores de qualquer ato educativo.

Em seguida, podemos citar as metodologias diferenciadas como o ensino híbrido que atrela interatividade ao conhecimento no Ensino superior para polir melhores resultados, como descrito por Cerutti e Melo pela URI/RS; o uso de TIC de forma coerente, sem que haja contexto de entretenimento, mas de conhecimento e desenvolvimento pelos alunos na educação brasileira proposto por Prioste e Raiça FCLAr/Unesp e a comparação entre metodologias ativas e tradicionais pela UFS, por 
Carvalho e colaboradores. Heredero e Coqueiro pela Universidad de Alcalá de Henares abordam a inserção das TIC para atingir os discentes de uma maneira mais efetiva ao longo do processo de educação básica e superior e para formação docente, visto que a atualização vem sendo muito citada por expertizes. A proposta de Correio feita em prol do uso de ferramentas digitais em salas de aula para o ensino técnico (PRONATEC), de Bittencourt e Albino pela Faac/Unesp, apontando o uso de mídias digitais no processo de ensino-aprendizagem em escolas do ensino médio de Bauru através da visão docente e discente e de Sacramento e Andrade, pela UFRJ, trazendo por meio da geografia, a apropriação do conhecimento sobre tecnologia de informação e comunicação, assim o aluno pode acessar atividades autoexplicativas de qualquer lugar e a qualquer hora.

Ressaltaremos também a contribuição ao ensino de ciências utilizando TIC para produção de conhecimento elaborando vídeos digitais que acentuaram o aprendizado como método alternativo em escolas municipais por Vieira da UFPE e o uso do cinema digital na promoção da igualdade de gênero na escola a partir de debates entre estudantes, fruto de um projeto de extensão realizado pela UFRPE por Mello e colaboradores.

Educomunicação é uma área que utiliza o uso de mídias na educação; é o encontro da educação com a comunicação e pode ser trabalhada em qualquer ambiente de formação. Sua utilização dos meios de comunicação para gerar conteúdo de informação e educação é colocada como importante fator na formação docente em um trabalho da USP por Santos.

Esta edição traz também textos que ressaltam a importância das relações humanizadas para formação e inserção do aluno no mercado de trabalho, como Bizelli e colaboradores da FCLar/Unesp, que apontam evidencias sobre a influência da afetividade na aprendizagem e a relação interpessoal entre professor e aluno como um dos fatores determinantes na construção da autoestima e, consequentemente, na eficácia do processo educativo. A valorização humana e superação de mecanismos de exclusão são colocados também nesta edição, a deficiência intelectual trabalhada por meio de tecnologias e práticas pedagógicas contemplam um Centro de Educação Especial realizado pela FCLAr/Unesp por Carneiro e Costa. Ainda, por meio de Martins - Unesp, vemos um trabalho sobre o estimulo ao desenvolvimento de criticidade e reflexão do aluno sem doutrinação, abordando aspectos marxistas em seu estudo e Normandia e Canto pela UNISA, atrelando o EaD a pedagogia da autonomia para formação de pessoas com cunho reflexivo e autônomo em níveis de graduação e pós-graduação. 
O Ensino a distância, muito expressivo atualmente, é colocado nesta edição. Dito como uma forma de ensino congruente ao ensino presencial, suas metodologias empregadas são similares ao ensino presencial, a aplicabilidade está na forma de comunicação.

Para isso trazemos alguns trabalhos pertinentes ao ensino a distância que contribuem de maneira significativa para o entendimento desse segmento que cresce cada dia mais. Apontamentos feitos por Vieira e colaboradores pela UFRJ, são discutidos a respeito do aumento do número de vagas comparado ao acesso em Instituições de nível superior, assim como a importância do material didático para consolidar a metodologia aplicada que acaba refletindo o nível de aprendizado pelo discente desenvolvido por Rosalin e colaboradores pela Faculdade Anhanguera no EAD e também discorrido por Martins e Félix pelo ISTA - Ce, através da percepção docente em relação as salas de aula com a preocupação do uso de uma didática inovadora para alcançar o ensino-aprendizado. A efetividade do ensino a distância na Enfermagem, um assunto muito discutido por especialistas é colocado em pauta, trazendo as principais características para sua aplicação no ensino, discorrido por Tanaka e colaboradores pela Unicamp.

Desejamos aos leitores, uma boa leitura!

AGRADECIMENTOS: Thaís Conte Vargas, pela revisão dos textos - redação, gramática e ortografia; Mariana Bulegon da Silva, pela revisão e tradução desta apresentação em Espanhol; Raquel Juliane Ribeiro de Faria, pela revisão e tradução em inglês; Ao Prof. Dr. Sebastião de Souza Lemes pela colaboração, confiança e avaliação deste dossiê, e a todos os autores que nos prestigiaram com seus textos, dessa forma, enaltecendo a pesquisa em educação e tecnologias.

\section{Como citar este texto:}

SANTOS CRUZ, José Anderson.; BERMEJO, Lucas Justiniano. Dossiê tecnologias e educação: novos olhares e percepções. Revista on line de Política e Gestão Educacional - RPGE, Araraquara, v.21, n. esp.1, p. 578-581, out./2017. Disponível em: <http://dx.doi.org/10.22633/rpge.v21.n.esp1.out.2017.10421>. ISSN: 1519-9029.

Submetido em: 01/02/2017

Aceite em: 01/03/2017

Aprovação final em: 15/07/2017 